\title{
Neurosteroids reduce social isolation-induced behavioral deficits: a proposed link with neurosteroid-mediated upregulation of BDNF expression
}

\author{
Mauricio Schüler Nin ${ }^{1,2}$, Luis A. Martinez ${ }^{1}$, Fabio Pibiri ${ }^{1}$, Marianela Nelson ${ }^{1}$ and Graziano Pinna ${ }^{1}$ * \\ 1 Department of Psychiatry, College of Medicine, Psychiatric Institute, University of Illinois at Chicago, Chicago, IL, USA \\ ${ }^{2}$ Coordenadoria de Aperfeicoamento de Pessoal de Nivel Superior Foundation, Ministry of Education of Brazil, Brasilia, Brazil
}

Edited by:

Kazuyoshi Tsutsui, Waseda University, Japan

Reviewed by:

Nicole Gallo-Payet, University of

Sherbrooke, Canada

James A. Carr, Texas Tech University, USA

\section{*Correspondence:}

Graziano Pinna, Department of Psychiatry, The Psychiatric Institute, University of Illinois at Chicago, 1601 W. Taylor Street, Chicago, IL 60612, USA.

e-mail:gpinna@psych.uic.edu
The pharmacological action of selective serotonin reuptake inhibitor antidepressants may include a normalization of the decreased brain levels of the brain-derived neurotrophic factor (BDNF) and of neurosteroids such as the progesterone metabolite allopregnanolone, which are decreased in patients with depression and posttraumatic stress disorders (PTSD). The allopregnanolone and BDNF level decrease in PTSD and depressed patients is associated with behavioral symptom severity. Antidepressant treatment upregulates both allopregnanolone levels and the expression of BDNF in a manner that significantly correlates with improved symptomatology, which suggests that neurosteroid biosynthesis and BDNF expression may be interrelated. Preclinical studies using the socially isolated mouse as an animal model of behavioral deficits, which resemble some of the symptoms observed in PTSD patients, have shown that fluoxetine and derivatives improve anxiety-like behavior, fear responses and aggressive behavior by elevating the corticolimbic levels of allopregnanolone and BDNF mRNA expression. These actions appeared to be independent and more selective than the action of these drugs on serotonin reuptake inhibition. Hence, this review addresses the hypothesis that in PTSD or depressed patients, brain allopregnanolone levels, and BDNF expression upregulation may be mechanisms at least partially involved in the beneficial actions of antidepressants or other selective brain steroidogenic stimulant molecules.

Keywords: allopregnanolone, $5 \alpha$-reductase type I, selective brain steroidogenic stimulants, $\mathrm{GABA}_{\mathrm{A}}$ receptors, BDNF anxiety, aggressive behavior, PTSD

\section{INTRODUCTION}

Impaired neurosteroid biosynthesis has been associated with numerous behavioral dysfunctions, which range from anxietyand depressive-like behaviors to aggressive behavior and changes in responses to contextual fear conditioning in rodent models of emotional dysfunction (Pinna et al., 2003, 2004, 2006, 2008; Uzunova et al., 2004, 2006; Jain et al., 2005; Martin-Garcia and Pallares, 2005; Kita and Furukawa, 2008; D'Aquila et al., 2010; Pinna, 2010). In clinical studies, decreases in the serum, plasma, and cerebrospinal fluid (CSF) content of neuroactive steroids, including the progesterone metabolite, allopregnanolone, which is a potent positive allosteric modulator of the action of $\gamma$-aminobutyric acid (GABA) at $\mathrm{GABA}_{\mathrm{A}}$ receptors (Puia et al., 1990, 2003; Lambert et al., 2003, 2009; Belelli and Lambert, 2005), are associated with several psychiatric disorders such as depression, anxiety spectrum disorders, posttraumatic stress disorders (PTSD), premenstrual dysphoric disorder, schizophrenia, and impulsive aggression (Rapkin et al., 1997; Romeo et al., 1998; Uzunova et al., 1998; Bloch et al., 2000; Nappi et al., 2001; Ströhle et al., 2002; Bäckström et al., 2003; Pinna et al., 2006; Rasmusson et al., 2006; Amin et al., 2007; Marx et al., 2009; Pearlstein, 2010). Thus, endogenous allopregnanolone exerts the physiological role of regulating emotional behavior by a potentiation of the inhibitory signal of the neurotransmitter GABA at $\mathrm{GABA}_{\mathrm{A}}$ receptors that are widely distributed in the glutamatergic neurons of the cortex and limbic areas, such as the hippocampus and the amygdala.

Allopregnanolone levels in the CSF of patients with PTSD and unipolar major depression were approximately half of those measured in the CSF of non-psychiatric patients (Uzunova et al., 1998; Rasmusson et al., 2006). Post-mortem studies confirmed that in depressed patients, the decrease of allopregnanolone is likely induced by a decrease in the expression of $5 \alpha$-reductase type I mRNA in the prefrontal-cortex (area BA9) compared with age- and sex-matched non-psychiatric subjects (Agis-Balboa et al., 2010; for a biosynthetic representation of allopregnanolone from progesterone by the action of $5 \alpha$-reductase, please see Figure 1). Our clinical studies support the hypothesis of a block in the synthesis of allopregnanolone in some individuals with PTSD and depression. This is also shown by the finding that allopregnanolone levels were the lowest among patients with comorbid PTSD and depression (Rasmusson et al., 2006). Interestingly, PTSD and major depressive disorder (MDD) are often comorbid and share multiple symptoms. Whereas PTSD is defined as a type of anxiety disorder that can occur as a result of experiencing 
a traumatic event that involved the threat of injury or death, several epidemiological studies show that depression diagnosed after trauma exposure is almost always comorbid with PTSD, which suggests that comorbid PTSD/MDD may likely be considered as a more severe PTSD (Breslau et al., 2002).

In depressed patients, treatment with selective serotonin reuptake inhibitors (SSRIs) including fluoxetine and fluvoxamine normalized CSF allopregnanolone content, which significantly correlated with the improvement in depressive symptoms (Uzunova et al., 1998). These data suggested that a deficit of GABAergic neurotransmission, likely caused by a downregulation of brain allopregnanolone biosynthesis in corticolimbic glutamatergic neurons, should be among the molecular mechanisms considered in the etiology of depression and PTSD. Upregulation of allopregnanolone biosynthesis appears to be a novel mechanism for the therapeutic effects of SSRIs (Pinna et al., 2009), at least for the anxiolytic, antidysphoric, and antiaggressive effects of these drugs. Likewise, neurosteroidogenic molecules that are unrelated to the SSRI class of drugs, including the ligands of the $18 \mathrm{kDa}$ translocase protein (TSPO), which is involved in the transport of cholesterol across the inner mitochondrial membrane and activation of neurosteroidogenesis (Rupprecht et al., 2010; Schüle et al., 2011), have been recently suggested as a new class of anxiolytic drugs. These drugs exert their anxiolytic effects by increasing the brain levels of allopregnanolone but unlike benzodiazepines, are devoid of unwanted side effects, including sedation, tolerance, and withdrawal symptoms (Serra et al., 1999; Rupprecht et al., 2009; Schüle et al., 2011). The advantage of a new generation of nonbenzodiazepine anxiolytics for the treatment of PTSD patients lies in the finding that PTSD patients fail to respond to the pharmacological effects of anxiolytic benzodiazepines (Gelpin et al., 1996; Viola et al., 1997; Davidson, 2004).

Interestingly, parallel investigations by several other laboratories have observed that in clinical studies, the brain-derived neurotrophic factor (BDNF) appears to play an important role in several psychiatric disorders, including PTSD and depression. BDNF plays a pivotal physiological role by maintaining trophism in the adult brain, affecting dendritic spine morphology, branching and synaptic plasticity, and long-term potentiation (LTP) with important implications for learning and memory and emotional behavior (Egan et al., 2003; Nagahara and Tuszynski, 2011). BDNF expressed in cortical and hippocampal pyramidal neurons can be released in the surrounding neuropil around cell bodies and dendrites and thus, becomes available for local utilization (Wetmore et al., 1994). The synthesis and release of BDNF by these pyramidal neurons provides evidence for both a paracrine and an autocrine role for BDNF and establishes a local source of trophic support for the maintenance of synaptic plasticity in the mature brain (Wetmore et al., 1994; Waterhouse and Xu, 2009; Cowansage et al., 2010). Because of these characteristics, BDNF may play an important role in the adaptation of corticolimbic areas to stress and to the action of antidepressants.

In psychiatric patients, BDNF expression was indeed decreased in both the post-mortem brain and in the blood cells of depressed patients. Further, the extent of BDNF downregulation positively correlated with the severity of depressive symptoms (Karege et al., 2002, 2005; Gonul et al., 2005; Piccinni et al., 2008). The levels of BDNF in the post-mortem brain of depressed patients were elevated in antidepressant-treated subjects (Chen et al., 2001; Aydemir et al., 2005; Gonul et al., 2005; Brunoni et al., 2008; Piccinni et al., 2008; Sen et al., 2008; Matrisciano et al., 2009). BDNF expression was also increased when patients were subjected to transcranial magnetic stimulation, vagus nerve stimulation, or electroconvulsive therapy (Bocchio-Chiavetto et al., 2006; Lang et al., 2006).

In protracted stress rodent studies, neurotrophins including BDNF have been identified as neuroendocrine effectors involved in the response to stress and in the behavioral dysfunction associated with anxiety and depression. Protracted stress in rodents induces morphological changes, such as decreased neurogenesis and neuronal atrophy (Sapolsky, 2000; McEwen et al., 2002; Duman, 2004; Tsankova et al., 2006). Social deprivation, a condition lacking social stimuli, for instance might represent a stressful condition triggering the emergence of dysfunctional emotional behavior characterized by increased emotionality and hypothalamic-pituitaryadrenal (HPA) axis reactivity in addition to reduced BDNF levels (Berry et al., 2011). Several antidepressant treatments have been shown to increase BDNF levels in the brain. Interestingly, antidepressant normalization of the stress-induced decrease of BDNF in mouse models appeared to be associated with long-term treatment with antidepressants (Nibuya et al., 1995; Shirayama et al., 2002; Russo-Neustadt et al., 2004; Alfonso et al., 2006). Of note, BDNF infusion into the hippocampus induces antidepressant-like effects in animal models of depression (Shirayama et al., 2002). On the other hand, mice lacking BDNF fail to respond to antidepressants (Monteggia et al., 2004).

Meanwhile, several preclinical studies observed that fluoxetine, paroxetine, sertraline, and other SSRIs increase the content of allopregnanolone in various rodent brain areas (Uzunov et al., 1996). Using the socially isolated mouse model of behavioral deficits that resemble symptoms of human anxiety disorders and PTSD (Pinna et al., 2003, 2004; reviewed in Pinna et al., 2006; Pinna, 2010 and Pinna et al., 2009), we have shown that corticolimbic allopregnanolone levels are decreased in association with the development of anxiety-like behaviors, resistance to sedation, and heightened aggression (Pinna et al., 2003, 2006; Nin et al., 2011). Several reports on the mechanisms by which SSRIs increase allopregnanolone biosynthesis confirmed the hypothesis that the behavioral effects of fluoxetine were unrelated to the serotonin reuptake inhibitory activity of these drugs (Pinna et al., 2003, 2004, 2009).

This review will examine whether neurosteroidogenesis and BDNF expression are interrelated and whether by elevating allopregnanolone biosynthesis, antidepressant therapy regulates BDNF expression.

\section{ALLOPREGNANOLONE AND BDNF BIOSYNTHESIS AND ACTION IN CORTICOLIMBIC NEURONS}

Independent of peripherally-derived progestins, allopregnanolone may be synthesized in the brain (Baulieu, 1981; Cheney et al., 1995; Baulieu et al., 2001; Guidotti et al., 2001; Stoffel-Wagner, 2001) from progesterone by the sequential action of two enzymes: $5 \alpha$-reductase type $\mathrm{I}$, which reduces progesterone to $5 \alpha$-dihydroprogesterone ( $5 \alpha-\mathrm{DHP})$, and is the rate-limiting step 


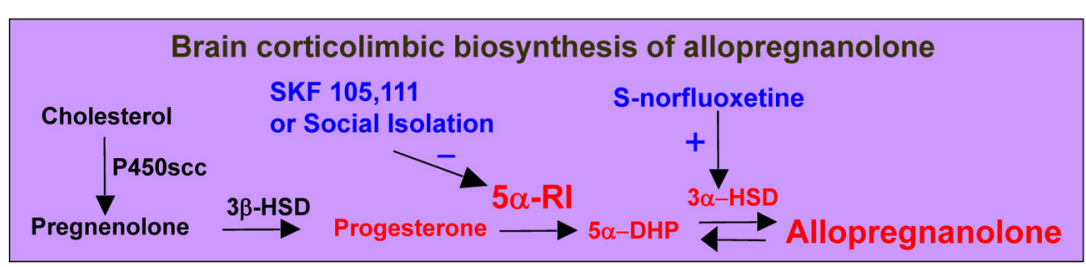

FIGURE 1 | In the brain, allopregnanolone is synthesized from progesterone by the sequential action of: (i) $5 \alpha$-reductase type I ( $5 \alpha-\mathrm{RI})$, which reduces progesterone into $5 \alpha$-dihydroprogesterone ( $5 \alpha$-DHP) and functions as the rate-limiting step enzyme in allopregnanolone biosynthesis; and (ii) $3 \alpha$-hydroxysteroid dehydrogenase ( $3 \alpha-H S D)$, which either converts $5 \alpha$-DHP into allopregnanolone (reductive reaction) or allopregnanolone into $5 \alpha$-DHP (oxidative reaction)

$17 \beta$-( N,N-diisopropylcarbamoyl)-androstan-3,5-diene-3-carboxylic acid (SKF 105,111 ) is a potent competitive $5 \alpha-R I$ inhibitor (Cheney et al., 1995). $S$-norfluoxetine stimulates the accumulation of allopregnanolone likely by targeting 3 $\alpha$-HSD (Griffin and Mellon, 1999). P450 scc, P450 cholesterol side-chain cleavage; $3 \beta-H S D, 3 \beta$-hydroxysteroid dehydrogenase. enzyme in allopregnanolone biosynthesis (Figure 1); and $3 \alpha$ hydroxysteroid dehydrogenase ( $3 \alpha-\mathrm{HSD})$, which either converts $5 \alpha$-DHP into allopregnanolone (reductive reaction) or allopregnanolone into $5 \alpha$-DHP (oxidative reaction; Figure 1).

Allopregnanolone reaches physiologically relevant levels that modulate $\mathrm{GABA}_{\mathrm{A}}$ receptor neurotransmission (Puia et al., 1990, 1991, 2003; Majewska, 1992; Pinna et al., 2000; Lambert et al., 2003, 2009; Belelli and Lambert, 2005). Allopregnanolone potently (nM affinity) induces a positive allosteric modulation of the action of GABA at $\mathrm{GABA}_{\mathrm{A}}$ receptors (Puia et al., 1990, 1991; Lambert et al., 2003, 2009). The physiological relevance of endogenous allopregnanolone is underlined by its facilitation and fine-tuning of the efficacy of direct $\mathrm{GABA}_{\mathrm{A}}$ receptor activators and positive allosteric modulators of GABA effects at $\mathrm{GABA}_{\mathrm{A}}$ receptors (Pinna et al., 2000; Guidotti et al., 2001; Matsumoto et al., 2003; Puia et al., 2003).

Allopregnanolone potentiates GABA responses via two binding sites in the $\mathrm{GABA}_{\mathrm{A}}$ receptor that, respectively, mediate the potentiation and direct activation effects of allopregnanolone. Direct $\mathrm{GABA}_{\mathrm{A}}$ receptor activation is initiated by the binding of allopregnanolone at a site formed by interfacial residues between the $\alpha$ and $\beta$ subunits (Hosie et al., 2006). Binding of allopregnanolone at the potentiation site located in a cavity within the $\alpha$-subunit results in a marked enhancement of $\mathrm{GABA}_{\mathrm{A}}$ receptor activation (Hosie et al., 2006).

The localization of enzymes involved in allopregnanolone biosynthesis in the brain remained unclear until recent investigations in the mouse (Agis-Balboa et al., 2006, 2007; reviewed in Pinna et al., 2008). In our studies, $5 \alpha$-reductase and $3 \alpha$-HSD were shown to be highly expressed and colocalized in a regionspecific way in primary GABAergic and glutamatergic neurons (pyramidal neurons, granular cells, reticulo-thalamic neurons, medium spiny neurons of the striatum and nucleus accumbens, and Purkinje cells), and were virtually unexpressed in GABAergic interneurons and glial cells (Agis-Balboa et al., 2006, 2007). Allopregnanolone synthesized in glutamatergic cortical or hippocampal pyramidal neurons or in granular cells of the dentate gyrus may be secreted in a paracrine manner by which allopregnanolone may reach $\mathrm{GABA}_{\mathrm{A}}$ receptors located in the synaptic membranes of other cortical or hippocampal pyramidal neurons (Figure 2, arrow 1). It could also occur in an autocrine fashion, which would allow allopregnanolone to act locally by binding post-synaptic or extra-synaptic $\mathrm{GABA}_{\mathrm{A}}$ receptors located on the same dendrites or cell bodies of the cortical or hippocampal pyramidal neuron in which allopregnanolone was synthesized (Agis-Balboa et al., 2006; Figure 2, arrow 2). Allopregnanolone might also diffuse laterally into synaptosome membranes of the cell bodies or dendritic arborization of glutamatergic neurons in which it is produced to attain intracellular access to specific neurosteroid binding sites of $\mathrm{GABA}_{\mathrm{A}}$ receptors (Akk et al., 2005; Agis-Balboa et al., 2006; Figure 2, arrow 3). Allopregnanolone and $5 \alpha$-dihydroprogesterone ( $5 \alpha$-DHP) may also affect intracellular signaling regulating gene expression, including BDNF expression (Figure 2, arrow 4).

The pro- and mature-forms of BDNF are synthesized and can be released from neurons by either a constitutive secretion or activity-dependent release (Mowla et al., 1999). Mature BDNF appears to be the most abundant form and that of highest physiological significance in the adult brain (Matsumoto et al., 2008; Rauskolb et al., 2010). Also, it is widely distributed in the forebrain and in most of cortical and limbic regions, including the cortex and hippocampus (reviewed in Nagahara and Tuszynski, 2011). Upon release, BDNF binds to two different receptors, the tropomyosin-related kinase receptor type $\mathrm{B}$ (TRKB), and the p75 receptor (Soppet et al., 1991). The most widely expressed BDNF receptor across various brain areas, TRKB is considered highly significant for BDNF functional actions in adulthood due to its higher binding affinity with BDNF and brain regional distribution (reviewed in Nagahara and Tuszynski, 2011). On the other hand, in the adult brain the BDNF low-affinity p75 receptor is expressed in basal forebrain cholinergic neurons and in a few cortical neurons (Lu et al., 1989). Interestingly, while mature BDNF binds with higher affinity to TRKB receptors, pro-BDNF has a higher affinity binding for p75 receptors. This difference in the binding of the two forms of BDNF is pivotal in terms of function. In fact, whereas the mature form of BDNF, by binding to TRKB, induces important physiological roles, including neuronal survival and the activation of several genes such as the cyclic AMP-response element-binding protein (CREB), the binding of pro-BDNF to p75 receptors has opposite effects, supporting apoptotic signaling (Koshimizu et al., 2010). The local release of BDNF in corticolimbic neurons may also regulate behavior by a rapid action on neurotransmitter systems (see also Figure 2). 


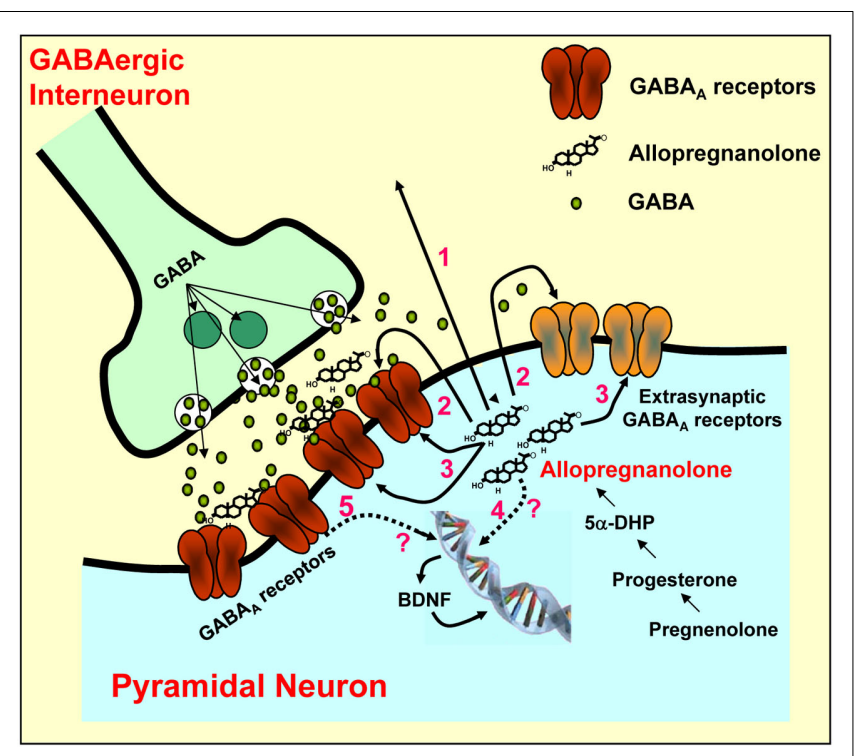

FIGURE 2 | Allopregnanolone biosynthesis and action on GABA receptors located on synaptic membranes of cortical pyramidal neurons. GABA, after been released from GABAergic interneurons, binds to and activates post-synaptic and extra-synaptic $\mathrm{GABA}_{\mathrm{A}}$ receptors. Allopregnanolone facilitates the synaptic inhibitory action of GABA at post-synaptic and extra-synaptic $\mathrm{GABA}_{\mathrm{A}}$ receptors by a paracrine (arrow 1) or autocrine (arrow 2) mechanism or may access $\mathrm{GABA}_{A}$ receptors by acting at the intracellular sites (arrow 3 ) of the $\mathrm{GABA}_{A}$ receptors. Finally, allopregnanolone may affect the expression of target genes, including BDNF, directly (arrow 4) or indirectly (arrow 5) by acting at $\mathrm{GABA}_{A}$ receptors. BDNF may be released and induce rapid effects at synapses via altering ion channels, or may exert intracellular genomic actions. Modified from Pinna et al. (2008).

\section{BEHAVIORAL DYSFUNCTIONS ASSOCIATED WITH SOCIAL ISOLATION}

Exposure of mice or rats to protracted social isolation stress for 4-8 weeks induces a decrease in allopregnanolone levels in several corticolimbic structures as a result of a downregulation of the mRNA and protein expression of $5 \alpha$-reductase type I (Matsumoto et al., 1999; Serra et al., 2000; Pinna et al., 2003; Bortolato et al., 2011; reviewed in Matsumoto et al., 2007; Pinna, 2010). $5 \alpha$-reductase is specifically decreased in cortical pyramidal neurons of layers V-VI, in hippocampal CA3 pyramidal neurons and glutamatergic granular cells of the dentate gyrus, and in the pyramidal-like neurons of the basolateral amygdala (Agis-Balboa et al., 2007). However, $5 \alpha$-reductase fails to change in GABAergic neurons of the reticular thalamic nucleus, central amygdala, cerebellum, or in the medium spiny neurons of the caudatus and putamen (Agis-Balboa et al., 2007). The decrease of $5 \alpha$-reductase in the above-mentioned brain areas resulted in a reduction of allopregnanolone levels (Pibiri et al., 2008).

Allopregnanolone biosynthesis appears to be a pivotal biomarker of behavioral deficits, including aggression, anxiety-like behavior, and changes in fear expression induced in rodent models of depression and anxiety spectrum disorders (Dong et al., 2001; Pinna et al., 2003, 2006, 2009; Uzunova et al., 2004, 2006; Pinna, 2010). In our laboratory, we have used socially isolated mice to establish an association between allopregnanolone biosynthesis and behavioral deficits as well as their reversal following pharmacological treatment (Matsumoto et al., 2003; Pinna et al., 2006, 2009; Pibiri et al., 2008; Nelson and Pinna, 2011). In mice socially isolated for a period of up to 8 weeks, we have demonstrated a timedependent increase in aggressive behavior over the first 4 weeks of isolation accompanied by a time-dependent decrease of corticolimbic allopregnanolone levels (Pinna et al., 2003, 2004, 2006, 2008; Pinna, 2010). Similarly, socially isolated mice exposed to a classical fear conditioning paradigm showed enhanced conditioned contextual but not explicitly cued fear responses compared with group-housed mice (Pibiri et al., 2008; Pinna et al., 2008). The time-related increase of contextual fear responses correlated with the downregulation of $5 \alpha$-reductase mRNA and protein expression observed in several corticolimbic areas, such as the frontal cortex, the hippocampus, and the amygdala (Pibiri et al., 2008). Likewise, social isolation in mice results in anxiety-like behavior (Pinna et al., 2006; Nin et al., 2011).

Pharmacological treatment with allopregnanolone dosedependently decreased aggression in a manner that correlated with an increase in corticolimbic allopregnanolone content (Pinna et al., 2003). These antiaggressive effects of allopregnanolone were confirmed by experiments in which allopregnanolone was directly infused into the basolateral amygdala, which increased the levels of basolateral amygdala and hippocampus allopregnanolone (Nelson and Pinna, 2011).

Allopregnanolone also normalized the exaggerated contextual fear responses and anxiety of socially isolated mice (Pibiri et al., 2008). Administration of the potent $5 \alpha$-reductase competitive inhibitor SKF 105,111 to normal group-housed mice (Cheney et al., 1995; Pinna et al., 2000, 2008; Pibiri et al., 2008) rapidly $(\sim 1 \mathrm{~h})$ decreased levels of allopregnanolone in the olfactory bulb, frontal cortex, hippocampus, and amygdala by $80-90 \%$ (Pibiri et al., 2008; Pinna et al., 2008) in association with a dose-dependent increase of conditioned contextual fear responses (Pibiri et al., 2008). The effects of SKF 105,111 on conditioned contextual fear responses were reversed by administering allopregnanolone doses that normalized hippocampus allopregnanolone levels (Pibiri et al., 2008). The anxiolytic and antidepressant properties of allopregnanolone have been extensively documented by several other laboratories using various rodent models of abnormal behavior (Bitran et al., 1991; Wieland et al., 1991; Rodgers and Johnson, 1998; Frye and Rhodes, 2006; Engin and Treit, 2007; Nin et al., 2008; Frye et al., 2009; Deo et al., 2010).

\section{SSRIS ACT AS SELECTIVE BRAIN STEROIDOGENIC} STIMULANTS AND ABOLISH BEHAVIORAL ABNORMALITIES

Results obtained in our laboratory have suggested that administration of a racemic mixture of the $R$ - and $S$-isomers of fluoxetine induced increases in corticolimbic allopregnanolone levels and normalized the righting reflex loss induced by pentobarbital in mice (Pinna et al., 2003, 2004, 2009). Importantly, at the doses used, fluoxetine failed to change the behavior and allopregnanolone levels of group-housed mice (Pinna et al., 2003, 2004). Thus, we hypothesized that fluoxetine could ameliorate the behavioral deficits of socially isolated mice by upregulating corticolimbic allopregnanolone levels rather than by inhibiting serotonin 
reuptake. This hypothesis was investigated using the $R$ - and $S$ stereoisomers of fluoxetine and norfluoxetine as pharmacological tools. We expected that these drugs would stereospecifically upregulate corticolimbic allopregnanolone content but have no stereoselectivity with regard to inhibition of 5-HT reuptake. Fluoxetine dose-dependently and stereospecifically normalized the duration of pentobarbital-induced sedation and reduced aggressiveness, fear responses, and anxiety-like behavior at the same submicromolar doses that normalized the downregulation of brain allopregnanolone content in socially isolated mice (Pinna et al., 2003, $2004,2006,2008,2009)$. Interestingly, the $S$-stereoisomers of fluoxetine or norfluoxetine appeared to be three-to-sevenfold more potent than their respective $R$-stereoisomers and $S$-norfluoxetine was about fivefold more potent than $S$-fluoxetine. Importantly, the effective concentrations (EC50s) of $S$-fluoxetine and $S$ norfluoxetine that normalize brain allopregnanolone content are 10- ( $S$-fluoxetine) and 50-fold ( $S$-norfluoxetine) lower than their respective EC50s needed to inhibit 5-HT reuptake (Pinna et al., 2003, 2004, 2009; Pinna, 2010). Of note, the SSRI activity of $S$ or $R$-fluoxetine and of $S$ or $R$-norfluoxetine was devoid of stereospecificity (Pinna et al., 2003, 2004).

These studies have clearly demonstrated that in socially isolated mice the pharmacological actions of SSRIs are induced by their ability to act as selective brain steroidogenic stimulants (SBSSs), which suggests a novel and more selective mechanism for the behavioral action of this class of drugs.

\section{NEUROSTEROIDS AND NEUROSTEROIDOGENIC ANTIDEPRESSANTS REGULATE NEUROGENESIS AND NEURONAL SURVIVAL}

Adult neurogenesis in the hippocampus begins by dividing precursor cells originating in the subgranular zone (SGZ). Another brain structure characterized by intense neurogenesis is the subventricular zone (SVZ). The differentiation and integration of new neurons to the adult dentate gyrus plays an important role in plasticity and represents a fundamental step in hippocampus-dependent learning/memory processes and possibly affects emotional behavior (Deng et al., 2010).

A growing number of studies support a role for steroid hormones [progesterone, allopregnanolone, dehydroepiandrosterone (DHEA) and its sulfated form DHEAS, estradiol, and androgens] in neurogenesis and cellular survival. Stem cells with multi differentiation potential for neuronal phenotypes are influenced by steroid hormones, such as regulating gene expression by binding to intracellular steroid receptors, activation of intracellular pathways involving kinases or intracellular calcium signaling, and modulation of receptors for neurotransmitters (reviewed in Velasco, 2011). Interestingly, steroid hormones can even substitute for modulate the action of growth factors and also directly influence self-renewal, proliferation, differentiation, or cell death of neurogenic stem cells.

Several environmental or internal factors affect neurogenesis in the hippocampus, among them social stress, including protracted social isolation, potently decreases neurogenesis (Dranovsky et al., 2011). Likewise, several stress-induced rodent models of depression show impaired neurogenesis (Coyle and Duman, 2003; Kempermann and Kronenberg, 2003). On the other hand, environmental enrichment, exercise, learning, and antidepressant treatments are able to increase the number, differentiation, and survival of newborn hippocampal neurons (Kempermann and Gage, 1998; van Praag et al., 1999; Leuner et al., 2004; Dranovsky and Hen, 2006). Interestingly, the pharmacological effects of neurosteroidogenic antidepressants can be abolished by reducing dentate gyrus neurogenesis (Santarelli et al., 2003; David et al., 2009), suggesting that the pharmacological effects of antidepressants may include the stimulation of neuronal progenitor cells, which has been reported in studies with rodent, human, and non-human primate hippocampus (Kempermann and Kronenberg, 2003; Boldrini et al., 2009). The adult amygdala shows signs of mixed activity-dependent plasticity with reduced numbers of microglia and a low level of proliferation and limited changes over time in neuronal and glial immunocytochemical properties (Ehninger et al., 2011). However, the basolateral amygdala seems to play a role in antidepressant-mediated hippocampal cell proliferation and survival as demonstrated by studies in rodents in which only when the basolateral amygdala was lesioned, did fluoxetine have a positive effect on hippocampal cell survival and antidepressant action (Castro et al., 2010).

Glucocorticoids have been shown to exert a primary and permissive regulatory role in hippocampal neurogenesis. Whereas stress-induced increased glucocorticoid levels reduce the proliferation of progenitor cells in the dentate gyrus, the reduction of their levels following adrenalectomy enhances neurogenesis (Wong and Herbert, 2004). DHEA and DHEAS also promote neurogenesis and neuronal survival. Given to rats, DHEA stimulated progenitor cell division and counteracted the suppressive effects of corticosterone (Karishma and Herbert, 2002). In another study, DHEA and DHEAS increased neurogenesis in the dentate gyrus, likely by increasing the concentrations of BDNF. A single administration of DHEA or DHEAS changed regional brain concentrations of BDNF within $5 \mathrm{~h}$ (Naert et al., 2007). DHEA decreased BDNF content in the hippocampus but not in the amygdala and increased BDNF in the hypothalamus. DHEAS first decreased BDNF after $30 \mathrm{~min}$ post-injection and increased BDNF after $3 \mathrm{~h}$ in the hippocampus. A biphasic increase in BDNF in the amygdala and decreased BDNF in the hypothalamus was also reported (Naert et al., 2007). This work suggests that DHEA and DHEAS affect BDNF levels by different mechanisms with unclear effects on neurogenesis and neuronal survival. DHEAS promoted survival of adult human cortical brain tissue in vitro (Brewer et al., 2001). DHEAS was as effective as the human recombinant fibroblast growth factor (FGF2) in promoting survival of neuron-like cells. DHEAS and FGF2 were synergistic in increasing cell survival (Brewer et al., 2001). Interestingly, DHEA showed a synergistic effect with antidepressants, in fact, it can render an otherwise ineffective dose of fluoxetine capable of increasing progenitor cell proliferation to the same extent as doses four times higher, which supports a role for DHEA as a useful adjunct therapy for depression (Pinnock et al., 2009).

Progesterone and progesterone metabolites, including allopregnanolone, also play a pivotal role on neurogenesis and neuronal survival. In the dentate gyrus of adult male mice, administration of progesterone increased the number of cells by twofold, 
likely by enhancing cell survival of newborn neurons (Zhang et al., 2010). The effects of progesterone appeared to be partially mediated by binding to progesterone receptors, as suggested by the fact that the $5 \alpha$-reductase inhibitor finasteride failed to prevent this effect, which was instead partially blocked by the progesterone antagonist RU486 (Zhang et al., 2010). In an in vitro study, both progesterone and allopregnanolone promoted human and rat neural progenitor cell proliferation. Allopregnanolone showed greater efficacy at the same concentration (Wang et al., 2005). In in vivo studies, allopregnanolone increased BrdU incorporation in the 3-month-old mouse hippocampal SGZ as well as in the SVZ (Brinton and Wang, 2006; Wang et al., 2010). These data suggested that for both neuroprotection and also likely for neurogenesis, allopregnanolone is the preliminary active agent. The role of allopregnanolone on neurogenesis was additionally tested on cerebellar granule cells. Allopregnanolone increased the proliferation of immature cerebellar granular cells taken from 6- to 8-day-old pups. This effect was abolished by bicuculline and picrotoxin (antagonists of $\mathrm{GABA}_{\mathrm{A}}$ receptors) and by nifedipine (dihydropyridine L-type-calcium channel blocker), which suggested that allopregnanolone increases DNA synthesis through a $\mathrm{GABA}_{\mathrm{A}}$ receptor-mediated activation (Keller et al., 2004).

Progesterone synthesized in Schwann cells also exerts important effects in the peripheral nervous system by promoting myelination, likely by an action mediated through progesterone receptors, although allopregnanolone also plays a role. Interestingly, progesterone stimulated myelin-specific proteins [e.g., protein 0 (P0) and the peripheral myelin protein-22 (PMP-22)] (Désarnaud et al., 1998; Melcangi et al., 1998, 1999; Notterpek et al., 1999) and increased the expression of Krox-20, a transcription factor crucially involved in myelination in the peripheral nervous system (Guennoun et al., 2001, reviewed in Mellon, 2007). As mentioned above, some effects on the expression of the myelin basic protein were likely mediated through allopregnanolone, as demonstrated by a study in which the use of finansteride to inhibit $5 \alpha$-reductase also partially inhibited the effects of progesterone. The involvement of allopregnanolone in myelination was further demonstrated by the finding that bicuculline inhibited the effect of allopregnanolone, providing evidence that allopregnanolone was involved in the increased expression of myelin basic proteins.

Hence, allopregnanolone has pronounced neuroprotective actions, increases myelination, and enhances neurogenesis and cell survival. Evidence suggests that allopregnanolone dysregulation may play a role in the pathophysiology of Alzheimer's disease and other neurodegenerative disorders, as demonstrated by data that allopregnanolone is reduced in the prefrontal and temporal cortex of patients with Alzheimer's disease compared to cognitively intact male control subjects and inversely correlated with the neuropathological disease stages. Thus, the normal age-related decline of allopregnanolone or its decline and that of other neurosteroids in psychiatric or neurological disorders (e.g., Alzheimer's disease) may trigger the subsequent decrease of neurogenesis and decreased expression of growth factors (Wang et al., 2008). Alternatively, the restored brain content of allopregnanolone following treatment with a steroidogenic drugs reverses neurogenesis downregulation and improves emotional and cognitive function (Santarelli et al., 2003; David et al., 2009).

\section{RELATIONSHIP BETWEEN BDNF AND ALLOPREGNANOLONE IN CORTICOLIMBIC NEURONS}

Decreased levels of BDNF have been implicated in the mechanisms underlying the clinical manifestations of PTSD and depression and also in an impairment of cognitive function in neurologic and psychiatric disorders following protracted stressful events. A hyperactive HPA axis and higher levels of circulating glucocorticoids have been associated with dysfunctional emotional behavior that can be normalized by antidepressant treatment (Holsboer and Barden, 1996; Mason and Pariante, 2006). It has been well established that protracted stressful events affecting emotional behaviors also decrease the levels of neurotrophins, including BDNF. Both PTSD and depressed patients express decreased levels of BDNF in the hippocampus and plasma (Sen et al., 2008). Of note, PTSD and depression have consistently been associated with decreased hippocampal volume with no differences in total cerebral volume or functional impairment (Sheline et al., 1996, 2002; Schmahl et al., 2009; Acheson et al., 2011). Studies aimed at identifying the functional significance of hippocampal volume loss demonstrated an association between hippocampal volume decrease and memory loss (Nagahara and Tuszynski, 2011). Altogether, these studies suggest that depression and PTSD are associated with hippocampal atrophy. Therapy using neurosteroidogenic antidepressants resulted in an improvement of PTSD and depressive symptoms and in a significant improvement in mean hippocampal volume (Vermetten et al., 2003; Nagahara and Tuszynski, 2011). In several studies, these neurosteroidogenic antidepressants have been reported to upregulate serum and hippocampal BDNF levels in post-mortem brains, which correlated with improved symptoms (Chen et al., 2001; Shimizu et al., 2003; Sen et al., 2008). Similar results were reported in individuals who received electroconvulsive therapy (Altar et al., 2003). Thus, these results suggest that antidepressant-mediated BDNF upregulation may counteract hippocampal atrophy by stimulating dendritic spine arborization and morphology and neurogenesis.

Several stress models in rodents, including acute or protracted restrain stress, resulted in decreased expression levels of hippocampal BDNF (reviewed in Smith et al., 1995; Ueyama et al., 1997; Tapia-Arancibia et al., 2004). Protracted social isolation is also a powerful stressful condition that would account for several dysfunctional emotional phenotypes associated with reduced expression of BDNF. For instance, social isolation in mice increased emotionality and HPA axis levels while reducing expression of BDNF levels (Berry et al., 2011). Isolation of rats at weaning reduced immobility time in the forced swim test, decreased sucrose intake and preference, and downregulated both BDNF and activityregulated cytoskeletal associated protein (Arc) in the hippocampus (Pisu et al., 2011). Likewise, a prolonged period of partial social isolation can modify BDNF protein concentrations selectively in the hippocampus with no changes in prefrontal cortices and striata. In this study, housing condition had no effect on basal plasma corticosterone (Scaccianoce et al., 2006).

Interestingly, plasticity in corticolimbic circuits is a prerequisite for triggering extinction of fear conditioning responses (Egan 
et al., 2003; Quirk and Milad, 2010). In these circuits, BDNF mediates plasticity and can be epigenetically regulated in a manner that correlates with fear extinction (Bredy et al., 2007). Accordingly, mice with a global deletion of one BDNF allele or with a forebrain-restricted deletion of both alleles show deficits in cognition, anxiety-like behavior, and elevated aggressive behavior (Rios et al., 2001). BDNF-restricted knockout mice instead exhibited elevated aggression and social dominance but did not show changes in anxiety-like behaviors (Ito et al., 2011).

Relying on these reports and on clinical and preclinical studies from our own group, we hypothesized that in PTSD and depressed patients who show a decrease of CSF allopregnanolone levels, antidepressant-induced allopregnanolone level upregulation was involved in the antidepressant mechanisms underlying the elevation of BDNF levels. Part of this hypothesis was that allopregnanolone regulates BDNF expression. Studies conducted in our laboratory in socially isolated mice have shown that a decrease of corticolimbic allopregnanolone levels is associated with decreased levels of corticolimbic BDNF mRNA expression (Nelson et al., 2010). We found that allopregnanolone levels and BDNF mRNA expression are downregulated in the same brain areas, namely the medial frontal cortex, hippocampus, and BLA and fail to change in the cerebellum and striatum (Pibiri et al., 2008; Nelson et al., 2010).

To test whether these neurochemical deficits were associated with behavioral dysfunctions (exaggerated contextual fear conditioning and impaired extinction), mice were exposed to a novel environment (i.e., context, a training chamber) and were allowed to explore it for $2 \mathrm{~min}$. After this time, they received an acoustic tone (i.e., conditioned stimulus, CS; $30 \mathrm{~s}, 85 \mathrm{~dB}$ ) coterminated with an unconditioned stimulus (US; electric footshock, $2 \mathrm{~s}, 0.5 \mathrm{~mA}$ ). The tone plus the foot shock were repeated three times every $2 \mathrm{~min}$. After the last tone + shock delivery, mice were allowed to explore the context for an additional minute prior to removal from the training chamber (total of $8 \mathrm{~min}$ ). On reexposure to the context $24 \mathrm{~h}$ later, the mice displayed a conditioned fear response, including sustained freezing behaviors. Freezing behavior, defined by the absence of any movement except for those related to respiration while the animal is in a stereotyped crouching posture (Pibiri et al., 2008), was measured for $5 \mathrm{~min}$ without tone or footshock presentation. Socially isolated mice also exhibited delayed and incomplete extinction of fear responses, which was assessed by exposing mice to the conditioning chamber on five consecutive days. The decrease of corticolimbic allopregnanolone levels and BDNF mRNA expression were also associated with changes in anxiety-like behavior and aggressiveness, which were assessed by using an elevated plus maze and the residentintruder test, respectively (Pinna et al., 2003, 2006; Nin et al., 2011).

Of note, in socially isolated mice we further studied the mean of spine density and the percentage of mature spines in layer III of the frontal cortex. Spine density was lower for socially isolated mice along the entire extent of the apical and basilar dendrites. Socially isolated mice also had a lower percentage of mature spines on both the apical and basilar dendrites. For the apical dendrite, the greatest decrease in percentage of mature spines for isolated mice was in the proximal portion of the dendrite, while for the basilar dendrite, the greatest decrease in percentage of mature spines was in the mid and distal portion of the dendrite (Tueting and Pinna, 2002 and manuscript in preparation).

Allopregnanolone treatment or $S$-norfluoxetine at concentrations sufficient to increase the levels of allopregnanolone in corticolimbic areas normalized BDNF mRNA expression in corticolimbic areas of socially isolated mice (Martinez et al., 2011). This treatment also improved dendritic spine morphology and behavioral deficits. $S$-norfluoxetine and allopregnanolone treatment induced a reduction of conditioned fear and facilitated fear extinction (Pibiri et al., 2008; Nelson et al., 2010). These treatments also prevented the reinstatement of fear memory following extinction, suggesting that allopregnanolone- or $S$-norfluoxetineinduced BDNF upregulation in corticolimbic areas strengthens extinction processing. Importantly, $S$-norfluoxetine and allopregnanolone actions on conditioned fear responses were mimicked by a single BDNF bilateral microinfusion into the BLA, which dose-dependently facilitated fear extinction and abolished the reinstatement of fear responses in the absence of locomotion impairment (Martinez et al., 2011). These observations support the hypothesis that by increasing allopregnanolone levels, SBSS drugs such as $S$-norfluoxetine may be involved in the regulation of corticolimbic BDNF expression and may induce longterm improvement in the behavioral dysfunctions that relate to PTSD.

These results originated in our laboratory are in accord with recent investigations suggesting that progesterone regulates BDNF expression. A study conducted with cerebral cortical explants has demonstrated that progesterone induces an upregulation of BDNF mRNA and protein expression (Kaur et al., 2007). Interestingly, allopregnanolone exerts complex acute actions in several corticolimbic structures following i.p. administration (Naert et al., 2007). In the hippocampus, the content of BDNF following an injection of allopregnanolone was first decreased after $30 \mathrm{~min}$ following the injection and significantly increased after $3 \mathrm{~h}$. In the amygdala, BDNF content was increased after 15-60 min from allopregnanolone, returned normal, and increased again after $5 \mathrm{~h}$. Finally, in the hypothalamus, BDNF levels were decreased (Naert et al., 2007). Collectively these studies suggest that part of the immediate or the long-term behavioral effects exerted by steroidogenic antidepressants may be explained by the effects of these drugs on allopregnanolone neosynthesis, which in turn may upregulate BDNF content and expression in corticolimbic neurons.

\section{CONCLUSION}

The incidence and prevalence of posttraumatic stress disorders and anxiety disorders are predicted to continue to increase, while current medications remain difficult due to the inefficacy of some antidepressants and benzodiazepines in the treatment of PTSD patients (Gelpin et al., 1996; Viola et al., 1997; Davidson, 2004).

We have observed that socially isolated mice, in addition to expressing a neurosteroidogenic deficit, which results in decreased levels of allopregnanolone, the most potent physiological positive modulator of $\mathrm{GABA}_{\mathrm{A}}$ receptor neurotransmission, also express a BDNF level downregulation in corticolimbic neurons. Treatment with allopregnanolone or with non-serotonergic doses of fluoxetine and norfluoxetine normalized both the levels of 
corticolimbic allopregnanolone and the mRNA expression of BDNF, which is associated with antianxiety and antiaggressive action as well as improvement of fear conditioning responses.

A new class of drugs, the SBSSs, which include molecules that share the ability to increase the brain levels of allopregnanolone, may have therapeutic potential for the treatment of PTSD and depression, which have been associated with a downregulation of brain allopregnanolone biosynthesis and BDNF expression.

Direct BDNF application to pharmacotherapy for psychiatric disorders is highly promising in the treatment of PTSD (Peters et al., 2010). However, the use of BDNF is difficult, particularly concerning the delivery of BDNF to the brain (Nagahara and Tuszynski, 2011). Thus, molecules that are able to

\section{REFERENCES}

Acheson, D. T., Gresack, J. E., and Risbrough, V. B. (2011). Hippocampal dysfunction effects on context memory: possible etiology for posttraumatic stress disorder. Neuropharmacology. doi: 10.1016/j.neuropharm.2011.04.029. [Epub ahead of print].

Agis-Balboa, R. C., Guidotti, A., Whitfield, H., and Pinna, G. (2010). Allopregnanolone biosynthesis is downregulated in the prefrontal cortex/Brodmann's area 9 (BA9) of depressed patients. 2010 Neuroscience Meeting, Abstr. 881.15.

Agis-Balboa, R. C., Pinna, G., Kadriu, B., Costa, E., and Guidotti, A. (2007). Down-regulation of neurosteroid biosynthesis in corticolimbic circuits mediates social isolationinduced behavior in mice. Proc. Natl. Acad. Sci. U.S.A. 104, 18736-18741.

Agis-Balboa, R. C., Pinna, G., Zhubi, A., Maloku, E., Veldic, M., Costa, E., and Guidotti, A. (2006). Characterization of brain neurons that express enzymes mediating neurosteroid biosynthesis. Proc. Natl. Acad. Sci. U.S.A. 103, 14602-14607.

Akk, G., Shu, H. J., Wang, C., Steinbach, J. H., Zorumski, C. F., Covey, D. F., and Mennerick, S. (2005). Neurosteroid access to the $\mathrm{GABA}_{\mathrm{A}}$ receptor. J. Neurosci. 25, 11605-11613.

Alfonso, J., Frick, L. R., Silberman, D. M., Palumbo, M. L., Genaro, A. M., and Frasch, A. C. (2006). Regulation of hippocampal gene expression is conserved in two species subjected to different stressors and antidepressant treatments. Biol. Psychiatry 59, 244-251.

Altar, C. A., Whitehead, R. E., Chen, R., Wörtwein, G., and Madsen, T. M. (2003). Effects of electroconvulsive seizures and antidepressant drugs on brain-derived neurotrophic factor protein in rat brain. Biol. Psychiatry 54, 703-709.
Amin, Z., Mason, G. F., Cavus, I., Krystal, J. H., Rothman, D. L., and Epperson, C. N. (2007). The interaction of neuroactive steroids and GABA in the development of neuropsychiatric disorders in women. J. Psychopharmacol. (Oxford) 21, 414-420.

Aydemir, O., Deveci, A., and Taneli, F. (2005). The effect of chronic antidepressant treatment on serum brainderived neurotrophic factor levels in depressed patients: a preliminary study. Prog. Neuropsychopharmacol. Biol. Psychiatry 29, 261-265.

Bäckström, T., Andreen, L., Birzniece, V., Björn, I., Johansson, I. M., Nordenstam-Haghjo, M., Nyberg, S., Sundström-Poromaa, I., Wahlström, G., Wang, M., and Zhu, D. (2003). The role of hormones and hormonal treatments in premenstrual syndrome. CNS Drugs 17, 325-342.

Baulieu, E. E. (1981). "Steroid hormones in the brain: several mechanisms," in Steroid Hormone Regulation of the Brain, eds K. Fuxe, J. A. Gustafson, and L. Wettenberg (Elmsford, NY: Pergamon), 3-14.

Baulieu, E. E., Robel, P., and Schumacher, M. (2001). Neurosteroids: beginning of the story. Int. Rev. Neurobiol. 46, 1-32.

Belelli, D., and Lambert, J. J. (2005). Neurosteroids: endogenous regulators of the $\mathrm{GABA}_{\mathrm{A}}$ receptor. Nat. Rev. Neurosci. 6, 565-575.

Berry, A., Bellisario, V., Capoccia, S., Tirassa, P., Calza, A., Alleva, E., and Cirulli, F. (2011). Social deprivation stress is a triggering factor for the emergence of anxietyand depression-like behaviours and leads to reduced brain BDNF levels in C57BL/6J mice. Psychoneuroendocrinology. PMID: 21974975. [Epub ahead of print].

Bitran, D., Hilvers, R. J., and Kellogg, C. K. (1991). Anxiolytic effects of 3 alpha-hydroxy-5 alpha[beta]pregnan-20-one: endogenous

endogenously stimulate BDNF levels, including SBSSs, may overcome the delivery challenge represented by administering BDNF directly.

Therefore, novel SBSS drugs that specifically increase corticolimbic allopregnanolone biosynthesis and stimulate BDNF expression in corticolimbic neurons appear to be highly promising as a new pharmacological class of future drugs for the treatment of depression, anxiety, and PTSD.

\section{ACKNOWLEDGMENTS}

This review was supported by the National Institute of Mental Health Grant MH 085999 (to G. Pinna). Nin MS supported by CAPES Foundation 2191-10-5 fellowship.

metabolites of progesterone that are active at the $\mathrm{GABA}_{\mathrm{A}}$ receptor. Brain Res. 561, 157-161.

Bloch, M., Schmidt, P. J., Danaceau, M. Murphy, J., Nieman, L., and Rubinow, D. R. (2000). Effects of gonadal steroids in women with a history of postpartum depression. Am. J. Psychiatry 157, 924-930.

Bocchio-Chiavetto, L., Zanardini, R. Bortolomasi, M., Abate, M., Segala, M., Giacopuzzi, M., Riva, M. A., Marchina, E., Pasqualetti, P., Perez, J., and Gennarelli, M. (2006). Electroconvulsive therapy (ECT) increases serum brain derived neurotrophic factor (BDNF) in drug resistant depressed patients. Eur. Neuropsychopharmacol. 16, 620-624.

Boldrini, M., Underwood, M. D., Hen, R., Rosoklija, G. B., Dwork, A. J., John Mann, J., and Arango, V. (2009). Antidepressants increase neural progenitor cells in the human hippocampus. Neuropsychopharmacology 34, 2376-2389.

Bortolato, M., Devoto, P., Roncada, P., Frau, R., Flore, G., Saba, P., Pistritto, G., Soggiu, A., Pisanu, S., Zappala, A., Ristaldi, M. S. Tattoli, M., Cuomo, V., Marrosu, F., and Barbaccia, M. L. (2011). Isolation rearing induced reduction of brain $5 \alpha$-reductase expression: relevance to dopaminergic impairments. Neuropharmacology 60, 1301-1308.

Bredy, T. W., Wu, H., Crego, C., Zellhoefer, J., Sun, Y. E., and Barad, M. (2007). Histone modifications around individual BDNF gene promoters in prefrontal cortex are associated with extinction of conditioned fear. Learn. Mem. 14, 268-276.

Breslau, N., Chase, G. A., and Anthony, J. C. (2002). The uniqueness of the DSM definition of posttraumatic stress disorder: implications for research. Psychol. Med. 32, 573-576.
Brewer, G. J., Espinosa, J., McIlhaney, M. P., Pencek, T. P., Kesslak, J. P., Cotman, C., Viel, J., and McManus, D. C. (2001). Culture and regeneration of human neurons after brain surgery. J. Neurosci. Methods 107, 15-23.

Brinton, R. D., and Wang, J. M. (2006). Preclinical analyses of the therapeutic potential of allopregnanolone to promote neurogenesis in vitro and in vivo in transgenic mouse model of Alzheimer's disease. Curr. Alzheimer Res. 3, 11-17.

Brunoni, A. R., Lopes, M., and Fregni, F. (2008). A systematic review and meta-analysis of clinical studies on depression and BDNF levels: implications for the role of neuroplasticity in depression. Int. J. Neuropsychopharmacol. 11, 1169-1180.

Castro, J. E., Varea, E., Márquez, C., Cordero, M. I., Poirier, G., and Sandi, C. (2010). Role of the amygdala in antidepressant effects on hippocampal cell proliferation and survival and on depression-like behavior in the rat. PLoS ONE 5, e8618. doi:10.1371/journal.pone.0008618

Chen, B., Dowlatshahi, D., MacQueen, G. M., Wang, J. F., and Young, L. T. (2001). Increased hippocampal BDNF immunoreactivity in subjects treated with antidepressant medication. Biol. Psychiatry 50, 260-265.

Cheney, D. L., Uzunov, D., Costa, E., and Guidotti, A. (1995). Gas chromatographic-mass fragmentographic quantitation of $3 \alpha$-hydroxy-5 $\alpha$-pregnan-20-one (allopregnanolone) and its precursors in blood and brain of adrenalectomized and castrated rats. J. Neurosci. 15, 4641-4650.

Cowansage, K. K., LeDoux, J. E., and Monfils, M. H. (2010). Brainderived neurotrophic factor: a dynamic gatekeeper of neural plasticity. Curr. Mol. Pharmacol. 3, 12-29. 
Coyle, J. T., and Duman, R. S. (2003). Finding the intracellular signaling pathways affected by mood disorder treatments. Neuron 38, 157-160.

D’Aquila, P. S., Canu, S., Sardella, M., Spanu, C., Serra, G., and Franconi, F. (2010). Dopamine is involved in the antidepressant-like effect of allopregnanolone in the forced swimming test in female rats. Behav. Pharmacol. 21, 21-28.

David, D. J., Samuels, B. A., Rainer, Q., Wang, J. W., Marsteller, D., Mendez, I., Drew, M., Craig, D. A., Guiard, B. P., Guilloux, J. P., Artymyshyn, R. P., Gardier, A. M., Gerald, C., Antonijevic, I. A., Leonardo, E. D., and Hen, R. (2009). Neurogenesisdependent and -independent effects of fluoxetine in an animal model of anxiety/depression. Neuron 62, 479-493.

Davidson, J. R. (2004). Use of benzodiazepines in social anxiety disorder, generalized anxiety disorder, and posttraumatic stress disorder. J. Clin. Psychiatry 65, 29-33.

Deng, W., Aimone, J. B., and Gage, F. H. (2010). New neurons and new memories: how does adult hippocampal neurogenesis affect learning and memory? Nat. Rev. Neurosci. 11, 339-350.

Deo, G. S., Dandekar, M. P., Upadhya, M. A., Kokare, D. M., and Subhedar, N. K. (2010). Neuropeptide Y $\mathrm{Y} 1$ receptors in the central nucleus of amygdala mediate the anxiolyticlike effect of allopregnanolone in mice: behavioral and immunocytochemical evidences. Brain Res. 1318, 77-86.

Désarnaud, F., Do Thi, A. N., Brown, A. M., Lemke, G., Suter, U., Baulieu, E. E., and Schumacher, M. (1998). Progesterone stimulates the activity of the promoters of peripheral myelin protein-22 and protein zero genes in Schwann cells. J. Neurochem. 71, 1765-1768.

Dong, E., Matsumoto, K., Uzunova, V., Sugaya, I., Costa, E., and Guidotti, A. (2001). Brain 5 $\alpha$ dihydroprogesterone and allopregnanolone synthesis in a mouse model of protracted social isolation. Proc. Natl. Acad. Sci. U.S.A. 98, 2849-2854.

Dranovsky, A., and Hen, R. (2006). Hippocampal neurogenesis: regulation by stress and antidepressants. Biol. Psychiatry 59, 1136-1143.

Dranovsky, A., Picchini, A. M., Moadel, T., Sisti, A. C., Yamada, A., Kimura, S., Leonardo, E. D., and Hen, R. (2011). Experience dictates stem cell fate in the adult hippocampus. $\mathrm{Neu}$ ron 70, 908-923.
Duman, R. S. (2004). Depression: a case of neuronal life and death? Biol. Psychiatry 56, 140-145.

Egan, M. F., Kojima, M., Callicott, J. H., Goldberg, T. E., Kolachana, B. S., Bertolino, A., Zaitsev, E., Gold, B., Goldman, D., Dean, M., Lu, B., and Weinberger, D. R. (2003). The BDNF val66met polymorphism affects activity-dependent secretion of BDNF and human memory and hippocampal function. Cell 112, 257-269.

Ehninger, D., Wang, L. P., Klempin, F., Römer, B., Kettenmann, H., and Kempermann, G. (2011). Enriched environment and physical activity reduce microglia and influence the fate of NG2 cells in the amygdala of adult mice. Cell Tissue Res. 345, 69-86.

Engin, E., and Treit, D. (2007). The anxiolytic-like effects of allopregnanolone vary as a function of intracerebral microinfusion site: the amygdala, medial prefrontal cortex, or hippocampus. Behav. Pharmacol. 18, 461-470.

Frye, C. A., Paris, J. J., and Rhodes, M. E. (2009). Increasing 3alpha,5alphaTHP following inhibition of neurosteroid biosynthesis in the ventral tegmental area reinstates antianxiety, social, and sexual behavior of naturally receptive rats. Reproduction 137, 119-128.

Frye, C. A., and Rhodes, M. E. (2006). Infusions of 5alphapregnan-3alpha-ol-20-one (3alpha,5alpha-THP) to the ventral tegmental area, but not the substantia nigra, enhance exploratory, antianxiety, social and sexual behaviours and concomitantly increase 3alpha,5alpha-THP concentrations in the hippocampus, diencephalon and cortex of ovariectomised oestrogen primed rats. J. Neuroendocrinol. 18, 960-975.

Gelpin, E., Bonne, O., Peri, T., Brandes, D., and Shalev, A. Y. (1996). Treatment of recent trauma survivors with benzodiazepines: a prospective study. J. Clin. Psychiatry 57, 390-394.

Gonul, A. S., Akdeniz, F., Taneli, F., Donat, O., Eker, C., and Vahip, S. (2005). Effect of treatment on serum brain-derived neurotrophic factor levels in depressed patients. Eur. Arch. Psychiatry Clin. Neurosci. 255, 381-386.

Griffin, L. D., and Mellon, S. H. (1999). Selective serotonin reuptake inhibitors directly alter activity of neurosteroidogenic enzymes. Proc. Natl. Acad. Sci. U.S.A. 96, 13512-13517.
Guennoun, R., Benmessahel, Y., Delespierre, B., Gouézou, M., Rajkowski, K. M., Baulieu, E. E., and Schumacher, M. (2001). Progesterone stimulates Krox-20 gene expression in Schwann cells. Brain Res. Mol. Brain Res. 90, 75-82.

Guidotti, A., Dong, E., Matsumoto, K., Pinna, G., Rasmusson, A. M., and Costa, E. (2001). The sociallyisolated mouse: a model to study the putative role of allopregnanolone and $5 \alpha$-dihydroprogesterone in psychiatric disorders. Brain Res. Rev. 37 , 110-115.

Holsboer, F., and Barden, N. (1996). Antidepressants and hypothalamicpituitary-adrenocortical regulation. Endocr. Rev. 17, 187-205.

Hosie, A. M., Wilkins, M. E., da Silva, H. M., and Smart, T. G. (2006). Endogenous neurosteroids regulate $\mathrm{GABA}_{\mathrm{A}}$ receptors through two discrete transmembrane sites. Nature 444, 486-489.

Ito, W., Chehab, M., Thakur, S., Li, J., and Morozov, A. (2011). BDNFrestricted knockout mice as an animal model for aggression. Genes Brain Behav. 10, 365-374.

Jain, N. S., Hirani, K., and Chopde, C. T. (2005). Reversal of caffeine-induced anxiety by neurosteroid 3-alphahydroxy-5-alpha-pregnane-20-one in rats. Neuropharmacology 48, 627-638.

Karege, F., Bondolfi, G., Gervasoni, N., Schwald, M., Aubry, J. M., and Bertschy, G. (2005). Low brain-derived neurotrophic factor (BDNF) levels in serum of depressed patients probably results from lowered platelet BDNF release unrelated to platelet reactivity. Biol. Psychiatry 57, 1068-1072.

Karege, F., Perret, G., Bondolfi, G., Schwald, M., Bertschy, G., and Aubry, J. M. (2002). Decreased serum brainderived neurotrophic factor levels in major depressed patients. Psychiatry Res. 109, 143-148.

Karishma, K. K., and Herbert, J. (2002). Dehydroepiandrosterone (DHEA) stimulates neurogenesis in the hippocampus of the rat, promotes survival of newly formed neurons and prevents corticosteroneinduced suppression. Eur. J. Neurosci. 16, 445-453.

Kaur, P., Jodhka, P. K., Underwood, W. A., Bowles, C. A., de Fiebre, N. C., de Fiebre, C. M. and Singh, M. (2007). Progesterone increases brain-derived neurotrophic factor expression and protects against glutamate toxicity in a mitogen-activated protein kinase- and phosphoinositide-
3 kinase-dependent manner in cerebral cortical explants. J. Neurosci. Res. 85, 2441-2449.

Keller, E. A., Zamparini, A., Borodinsky, L. N., Gravielle, M. C., and Fiszman, M. L. (2004). Role of allopregnanolone on cerebellar granule cells neurogenesis. Brain Res. Dev. Brain Res. 153, 13-17.

Kempermann, G., and Gage, F. H. (1998). Closer to neurogenesis in adult humans. Nat. Med.4,555-557.

Kempermann, G., and Kronenberg, G. (2003). Depressed new neuronsadult hippocampal neurogenesis and a cellular plasticity hypothesis of major depression. Biol. Psychiatry 54, 499-503.

Kita, A., and Furukawa, K. (2008). Involvement of neurosteroids in the anxiolytic-like effects of AC-5216 in mice. Pharmacol. Biochem. Behav. 89, 171-178.

Koshimizu, H., Hazama, S., Hara, T., Ogura, A., and Kojima, M. (2010). Distinct signaling pathways of precursor BDNF and mature BDNF in cultured cerebellar granule neurons. Neurosci. Lett. 473, 229-232.

Lambert, J. J., Belelli, D., Peden, D. R., Vardy, A. W., and Peters, J. A. (2003). Neurosteroid modulation of $\mathrm{GABA}_{\mathrm{A}}$ receptors. Prog. Neurobiol. 71, 67-80.

Lambert, J. J., Cooper, M. A., Simmons, R. D., Weir, C. J., and Belelli, D. (2009). Neurosteroids: endogenous allosteric modulators of $\mathrm{GABA}_{A}$ receptors. Psychoneuroendocrinology 34, S48-S58.

Lang, U. E., Bajbouj, M., Gallinat, J., and Hellweg, R. (2006). Brain-derived neurotrophic factor serum concentrations in depressive patients during vagus nerve stimulation and repetitive transcranial magnetic stimulation. Psychopharmacology (Berl.) 187, 156-159.

Leuner, B., Mendolia-Loffredo, S., Kozorovitskiy, Y., Samburg, D. Gould, E., and Shors, T. J. (2004). Learning enhances the survival of new neurons beyond the time when the hippocampus is required for memory. J. Neurosci. 24, 7477-7481.

Lu, B., Buck, C. R., Dreyfus, C. F., and Black, I. B. (1989). Expression of NGF and NGF receptor mRNAs in the developing brain: evidence for local delivery and action of NGF. Exp. Neurol. 104, 191-199.

Majewska, M. D. (1992). Neurosteroids: endogenous bimodal modulators of the $\mathrm{GABA}_{\mathrm{A}}$ receptor. Mechanism of action and physiological significance. Prog. Neurobiol. 38, 379-395. 
Martinez, L. A., Pibiri, F., Nelson, M., Nin, M. S., and Pinna, G. (2011). Selective brain steroidogenic stimulant (SBSS)-induced neurosteroid upregulation facilitates fear extinction and reinstatement of fear memory by a BDNF-mediated mechanism in a mouse model of PTSD. Society for Neuroscience 2011 Abstract, Washington, DC.

Martin-Garcia, E., and Pallares, M. (2005). The intrahippocampal administration of the neurosteroid allopregnanolone blocks the audiogenic seizures induced by nicotine. Brain Res. 1062, 144-150.

Marx, C. E., Keefe, R. S., Buchanan, R. W., Hamer, R. M., Kilts, J. D., Bradford, D. W., Strauss, J. L., Naylor, J. C., Payne, V. M., Lieberman, J. A., Savitz, A. J., Leimone, L. A., Dunn, L., Porcu, P., Morrow, A. L., and Shampine, L. J. (2009). Proof-of concept trial with the neurosteroid pregnenolone targeting cognitive and negative symptoms in schizophrenia. Neuropsychopharmacology 34, 1885-1903.

Mason, B. L., and Pariante, C. M. (2006). The effects of antidepressants on the hypothalamicpituitary-adrenal axis. Drug News Perspect. 19, 603-608.

Matrisciano, F., Bonaccorso, S., Ricciardi, A., Scaccianoce, S., Panaccione, I., Wang, L., Ruberto, A., Tatarelli, R., Nicoletti, F., Girardi, P., and Shelton, R. C. (2009). Changes in BDNF serum levels in patients with depression disorder (MDD) after 6 months treatment with sertraline, escitalopram, or venlafaxine. J. Psychiatr. Res. 43, 247-254.

Matsumoto, K., Nomura, H., Murakami, Y., Taki, K., Takahata, H., and Watanabe, H. (2003). Long-term social isolation enhances picrotoxin seizure susceptibility in mice: up-regulatory role of endogenous brain allopregnanolone in GABAergic systems. Pharmacol. Biochem. Behav. 75, 831-835.

Matsumoto, K., Puia, G., Dong, E., and Pinna, G. (2007). GABA A receptor neurotransmission dysfunction in a mouse model of social isolationinduced stress: possible insights into a nonserotonergic mechanism of action of SSRIs in mood and anxiety disorders. Stress 10, 3-12.

Matsumoto, K., Uzunova, V., Pinna, G., Taki, K., Uzunov, D. P., Watanabe, H., Mienvielle, J.-M., Guidotti, A., and Costa, E. (1999). Permissive role of brain allopregnanolone content in the regulation of pentobarbitalinduced righting reflex loss. Neuropharmacology 38, 955-963.
Matsumoto, T, Rauskolb, S., Polack, M., Klose, J., Kolbeck, R., Korte, M. and Barde, Y. A. (2008). Biosynthesis and processing of endogenous BDNF: CNS neurons store and secrete BDNF, not pro-BDNF. Nat. Neurosci. 11, 131-133.

McEwen, B. S., Magarinos, A. M., and Reagan, L. P. (2002). Structural plasticity and tianeptine: cellular and molecular targets. Eur. Psychiatry 17, 318-330.

Melcangi, R. C., Magnaghi, V., Cavarretta, I., Martini, L., and Piva, F. (1998). Age-induced decrease of glycoprotein Po and myelin basic protein gene expression in the rat sciatic nerve. Repair by steroid derivatives. Neuroscience 85, 569-578.

Melcangi, R. C., Magnaghi, V., Cavarretta, I., Zucchi, I., Bovolin, P., D’Urso, D., and Martini, L. (1999). Progesterone derivatives are able to influence peripheral myelin protein 22 and $\mathrm{P} 0$ gene expression: possible mechanisms of action. J. Neurosci. Res. 56, 349-357.

Mellon, S. H. (2007). Neurosteroid regulation of central nervous system development. Pharmacol. Ther. 116, 107-124.

Monteggia, L. M., Barrot, M., Powell, C. M., Berton, O., Galanis, V., Gemelli, T., Meuth, S., Nagy, A., Greene, R. W., and Nestler, E. J. (2004). Essential role of brain-derived neurotrophic factor in adult hippocampal function. Proc. Natl. Acad. Sci. U.S.A. 101, 10827-10832.

Mowla, S. J., Pareek, S., Farhadi, H. F., Petrecca, K., Fawcett, J. P., Seidah, N. G., Morris, S. J., Sossin, W. S., and Murphy, R. A. (1999). Differential sorting of nerve growth factor and brain-derived neurotrophic factor in hippocampal neurons. J. Neurosci. 19, 2069-2080.

Naert, G., Maurice, T., Tapia-Arancibia, L., and Givalois, L. (2007). Neuroactive steroids modulate HPA axis activity and cerebral brain-derived neurotrophic factor (BDNF) protein levels in adult male rats. Psychoneuroendocrinology 32, 1062-1078.

Nagahara, A. H., and Tuszynski, M. H. (2011). Potential therapeutic uses of BDNF in neurological and psychiatric disorders. Nat. Rev. Drug Discov. 10, 209-219.

Nappi, R. E., Petraglia, F., Luisi, S., Polatti, F., Farina, C., and Genazzani, A. R. (2001). Serum allopregnanolone in women with postpartum “blues". Obstet. Gynecol. 97, 77-80.
Nelson, M., Pibiri, F., and Pinna, G. (2010). Relationship between allopregnanolone (Allo) and reduced brain BDNF and reelin expression in a mouse model of posttraumatic stress disorders (PTSD). Soc. Neurosci. 2010 Abstr. 666.22

Nelson, M., and Pinna, G. (2011). S-norfluoxetine infused into the basolateral amygdala increases allopregnanolone levels and reduces aggression in socially isolated mice. Neuropharmacology 60 , 1154-1159.

Nibuya, M., Morinobu, S., and Duman, R. S. (1995). Regulation of BDNF and trkB mRNA in rat brain by chronic electroconvulsive seizure and antidepressant drug treatments. J. Neurosci. 15, 7539-7547.

Nin, M. S., Salles, F. B., Azeredo, L. A., Frazon, A. P., Gomez, R., and Barros, H. M. (2008). Antidepressant effect and changes of $\mathrm{GABA}_{\mathrm{A}}$ receptor gamma2 subunit mRNA after hippocampal administration of allopregnanolone in rats. J. Psychopharmacol. (Oxford) 22, 477-485.

Nin M. S., Martinez, L. A., Thomas, R., Nelson, M., and Pinna, G. (2011). Allopregnanolone and Snorfluoxetine decrease anxiety-like behavior in a mouse model of anxiety/depression. Trab. Inst. Cajal 83, 215-216.

Notterpek, L., Snipes, G. J., and Shooter E. M. (1999). Temporal expression pattern of peripheral myelin protein 22 during in vivo and in vitro myelination. Glia 25, 358-369.

Pearlstein, T. (2010). Premenstrual dysphoric disorder: out of the appendix. Arch. Womens Ment. Health 13, 21-23.

Peters, J., Dieppa-Perea, L. M., Melendez, L. M., and Quirk, G. J. (2010). Induction of fear extinction with hippocampal-infralimbic BDNF. Science 328, 1288-1290.

Pibiri, F., Nelson, M., Guidotti, A., Costa, E., and Pinna, G. (2008). Decreased allopregnanolone content during social isolation enhances contextual fear: a model relevant for posttraumatic stress disorder. Proc. Natl. Acad. Sci. U.S.A. 105, 5567-5572.

Piccinni, A., Marazziti, D., Catena, M., Domenici, L., Del Debbio, A., Bianchi, C., Mannari, C., Martini, C. Da Pozzo, E., Schiavi, E., Mariotti, A., Roncaglia, I., Palla, A., Consoli, G., Giovannini, L., Massimetti, G., and Dell'Osso, L. (2008). Plasma and serum brain-derived neurotrophic factor (BDNF) in depressed patients during 1 year of antidepressant treatments. J. Affect. Disord. 105, 279-283.

Pinna, G. (2010). In a mouse model relevant for post-traumatic stress disorder, selective brain steroidogenic stimulants (SBSS) improve behavioral deficits by normalizing allopregnanolone biosynthesis. Behav. Pharmacol. 21, 438-450.

Pinna, G., Agis-Balboa, R., Pibiri, F. Nelson, M., Guidotti, A., and Costa, E. (2008). Neurosteroid biosynthesis regulates sexually dimorphic fear and aggressive behavior in mice. Neurochem. Res. 33, 1990-2007.

Pinna, G., Costa, E., and Guidotti, A. (2004). Fluoxetine and norfluoxetine stereospecifically facilitate pentobarbital sedation by increasing neurosteroids. Proc. Natl. Acad. Sci. U.S.A. 101, 6222-6225.

Pinna, G., Costa, E., and Guidotti, A. (2006). Fluoxetine and norfluoxetine stereospecifically and selectively increase brain neurosteroid content at doses that are inactive on 5HT reuptake. Psychopharmacology (Berl.) 186, 362-372.

Pinna, G., Costa, E., and Guidotti, A. (2009). SSRIs act as selective brain steroidogenic stimulants (SBSSs) at low doses that are inactive on 5-HT reuptake. Curr. Opin. Pharmacol. 9, 24-30.

Pinna, G., Dong, E., Matsumoto, K., Costa, E., and Guidotti, A. (2003). In socially isolated mice, the reversal of brain allopregnanolone down-regulation mediates the anti-aggressive action of fluoxetine. Proc. Natl. Acad. Sci. U.S.A. 100, 2035-2040.

Pinna, G., Uzunova, V., Matsumoto, K., Puia, G., Mienville, J.-M., Costa, E., and Guidotti, A. (2000). Brain allopregnanolone regulates the potency of the $\mathrm{GABA}_{\mathrm{A}}$ receptor agonist muscimol. Neuropharmacology 39, 440-448.

Pinnock, S. B., Lazic, S. E., Wong, H. T., Wong, I. H., and Herbert, J. (2009). Synergistic effects of dehydroepiandrosterone and fluoxetine on proliferation of progenitor cells in the dentate gyrus of the adult male rat. Neuroscience 158, 1644-1651.

Pisu, M. G., Dore, R., Mostallino, M. C., Loi, M., Pibiri, F., Mameli, R., Cadeddu, R., Secci, P. P., and Serra, M. (2011). Down-regulation of hippocampal BDNF and Arc associated with improvement in aversive spatial memory performance in socially isolated rats. Behav. Brain Res. 222, 73-80. 
Puia, G., Mienville, J.-M., Matsumoto, K., Takahata, H., Watanabe, H., Costa, E., and Guidotti, A. (2003). On the putative physiological role of allopregnanolone on $\mathrm{GABA}_{\mathrm{A}}$ receptor function. Neuropharmacology 44 , 49-55.

Puia, G., Santi, M. R., Vicini, S., Pritchett, D. B., Purdy, R. H., Paul, S. M., Seeburg, P. H., and Costa, E. (1990). Neurosteroids act on recombinant human $\mathrm{GABA}_{\mathrm{A}}$ receptors. Neuron 4 , 759-765.

Puia, G., Vicini, S., Seeburg, P. H., and Costa, E. (1991). Influence of recombinant gamma-aminobutyric acid - a receptor subunit composition on the action of allosteric modulators of gammaaminobutyricacidgated Cl-currents. Mol. Pharmacol. 39, 691-696.

Quirk, G. J., and Milad, M. R. (2010). Neuroscience: editing out fear. Nature 463, 36-37.

Rapkin, A. J., Morgan, M., Goldman, L., Brann, D. W., Simone, D., and Mahesh, V. B. (1997). Progesterone metabolite allopregnanolone in women with premenstrual syndrome. Obstet. Gynecol. 90, 709-714.

Rasmusson, A. M., Pinna, G., Paliwal, P., Weisman, D., Gottschalk, C., Charney, D., Krystal, J., and Guidotti, A. (2006). Decreased cerebrospinal fluid allopregnanolone levels in women with posttraumatic stress disorder. Biol. Psychiatry 60, 704-713.

Rauskolb, S, Zagrebelsky, M., Dreznjak, A., Deogracias, R., Matsumoto, T., Wiese, S., Erne, B., Sendtner, M., Schaeren-Wiemers, N., Korte, M., and Barde, Y. A. (2010). Global deprivation of brain-derived neurotrophic factor in the CNS reveals an area-specific requirement for dendritic growth. J. Neurosci. 30, 1739-1749.

Rios, M., Fan, G., Fekete, C., Kelly, J., Bates, B., Kuehn, R., Lechan, R. M., and Jaenisch, R. (2001). Conditional deletion of brain-derived neurotrophic factor in the postnatal brain leads to obesity and hyperactivity. Mol. Endocrinol. 15, 1748-1757.

Rodgers, R. J., and Johnson, N. J. (1998). Behaviorally selective effects of neuroactive steroids on plus-maze anxiety in mice. Pharmacol. Biochem. Behav. 59, 221-232.

Romeo, E., Ströhle, A., Spalletta, G., di Michele, F., Hermann, B., Holsboer, F., Pasini, A., and Rupprecht, R. (1998). Effects of antidepressant treatment on neuroactive steroids in major depression. Am. J. Psychiatry 155, 910-913.
Rupprecht, R., Papadopoulos, V., Rammes, G., Baghai, T. C., Fan, J., Akula, N., Groyer, G., Adams, D., and Schumacher, M. (2010). Translocator protein $(18 \mathrm{kDa})$ (TSPO) as a therapeutic target for neurological and psychiatric disorders. Nat. Rev. Drug Discov. 9, 971-988.

Rupprecht, R., Rammes, G., Eser, D., Baghai, T. C., Schüle, C., Nothdurfter, C., Troxler, T., Gentsch, C., Kalkman, H. O., Chaperon, F., Uzunov, V., McAllister, K. H., Bertaina-Anglade, V., La Rochelle, C. D., Tuerck, D., Floesser, A., Kiese, B., Schumacher, M., Landgraf, R., Holsboer, F., and Kucher, K. (2009). Translocator protein (18 $\mathrm{kD})$ as target for anxiolytics without benzodiazepine-like side effects. Science 325, 490-493.

Russo-Neustadt, A. A., Alejandre, H., Garcia, C., Ivy, A. S., and Chen, M. J. (2004). Hippocampal brainderived neurotrophic factor expression following treatment with reboxetine, citalopram, and physical exercise. Neuropsychopharmacology 29, 2189-2199.

Santarelli, L., Saxe, M., Gross, C., Surget, A., Battaglia, F., Dulawa, S., Weisstaub, N., Lee, J., Duman, R., Arancio, O., Belzung, C., and Hen, R. (2003). Requirement of hippocampal neurogenesis for the behavioral effects of antidepressants. Science 301, 805-809.

Sapolsky, R. M. (2000). Glucocorticoids and hippocampal atrophy in neuropsychiatric disorders. Arch. Gen. Psychiatry 57, 925-935.

Scaccianoce, S., Del Bianco, P., Paolone, G., Caprioli, D., Modafferi, A. M., Nencini, P., and Badiani, A. (2006). Social isolation selectively reduces hippocampal brain-derived neurotrophic factor without altering plasma corticosterone. Behav. Brain Res. 168, 323-325.

Schmahl, C., Berne, K., Krause, A., Kleindienst, N., Valerius, G., Vermetten, E., and Bohus, M. (2009). Hippocampus and amygdala volumes in patients with borderline personality disorder with or without posttraumatic stress disorder. J. Psychiatry Neurosci. 34, 289-295.

Schüle, C., Eser, D., Baghai, T. C., Nothdurfter, C., Kessler, J. S., and Rupprecht, R. (2011). Neuroactive steroids in affective disorders: target for novel antidepressant or anxiolytic drugs? Neuroscience 191, 55-77.

Sen, S., Duman, R., and Sanacora, G. (2008). Serum brain-derived neurotrophic factor, depression, and antidepressant medications: metaanalyses and implications. Biol. Psychiatry 64, 527-532.

Serra, M., Madau, P., Chessa, M. F., Caddeo, M., Sanna, E., Trapani, G., Franco, M., Liso, G., Purdy, R. H., Barbaccia, M. L., and Biggio, G. (1999). 2-Phenyl-imidazo[1,2a]pyridine derivatives as ligands for peripheral benzodiazepine receptors: stimulation of neurosteroid synthesis and anticonflict action in rats. Br. J. Pharmacol. 127, 177-187.

Serra, M., Pisu, M. G., Littera, M., Papi, G., Sanna, E., Tuveri, F., Usala, L., Purdy, R. H., and Biggio, G. (2000). Social isolation-induced decreases in both the abundance of neuroactive steroids and $\mathrm{GABA}(\mathrm{A})$ receptor function in rat brain. J. Neurochem. 75, 732-740.

Sheline, Y. I., Mittler, B. L., and Mintun, M. A. (2002). The hippocampus and depression. Eur. Psychiatry 17, 300-305.

Sheline, Y. I., Wang, P. W., Gado, M. H., Csernansky, J. G., and Vannier, M. W. (1996). Hippocampal atrophy in recurrent major depression. Proc. Natl. Acad. Sci. U.S.A. 93, 3908-3913.

Shimizu, E., Hashimoto, K., Okamura, N., Koike, K., Komatsu, N., Kumakiri, C., Nakazato, M., Watanabe, H., Shinoda, N., Okada, S., and Iyo, M. (2003). Alterations of serum levels of brain-derived neurotrophic factor (BDNF) in depressed patients with or without antidepressants. Biol. Psychiatry 54, 70-75.

Shirayama, Y, Chen, A. C., Nakagawa, S., Russell, D. S., and Duman, R. S. (2002). Brain-derived neurotrophic factor produces antidepressant effects in behavioral models of depression. J. Neurosci. 22, 3251-3261.

Smith, M. A., Makino, S., Kvetnansky, R., and Post, R. M. (1995). Stress and glucocorticoids affect the expression of brain-derived neurotrophic factor and neurotrophin-3 mRNAs in the hippocampus. J. Neurosci. 15, 1768-1777.

Soppet, D, Escandon, E., Maragos, J., Middlemas, D. S., Reid, S. W., Blair, J., Burton, L. E., Stanton, B. R., Kaplan, D. R., Hunter, T., Nikolics, K., and Parada, L. F. (1991). The neurotrophic factors brain-derived neurotrophic factor and neurotrophin3 are ligands for the trkB tyrosine kinase receptor. Cell 65, 895-903.

Stoffel-Wagner, B. (2001). Neurosteroid metabolism in the human brain. Eur. J. Endocrinol. 145, 669-679.
Ströhle, A., Romeo, E., di Michele, F., Pasini, A., Yassouridis, A., Holsboer, F., and Rupprecht, R. (2002). $\mathrm{GABA}_{\mathrm{A}}$ receptor-modulationg neuroactive steroid composition in patients with panic disorder before and during paroxetine treatment. Am. J. Psychiatry 159, 145-147.

Tapia-Arancibia, L, Rage, F., Givalois, L., and Arancibia, S. (2004). Physiology of BDNF: focus on hypothalamic function. Front. Neuroendocrinol.25, 77-107.

Tsankova, N. M., Berton, O., Renthal, W., Kumar, A., Neve, R. L., and Nestler, E. J. (2006). Sustained hippocampal chromatin regulation in a mouse model of depression and antidepressant action. Nat. Neurosci. 9, 519-525.

Tueting, P., and Pinna, G. (2002). Behavior associated with an enriched environment and with social isolation in mice. Soc. Neurosci. 2002 Abstr. 106.12 .

Ueyama, T., Kawai, Y., Nemoto, K., Sekimoto, M., Toné, S., and Senba, E. (1997). Immobilization stress reduced the expression of neurotrophins and their receptors in the rat brain. Neurosci. Res. 28, 103-110.

Uzunov, D. P., Cooper, T. B., Costa, E., and Guidotti, A. (1996). Fluoxetine elicited changes in brain neurosteroid content measured by negative ion mass fragmentography. Proc. Natl. Acad. Sci. U.S.A. 93, 12599-12604.

Uzunova, V., Sampson, L., and Uzunov, D. P. (2006). Relevance of endogenous 3alpha-reduced neurosteroids to depression and antidepressant action. Psychopharmacology (Berl.) 186, 351-361

Uzunova, V., Sheline, Y., Davis, J. M., Rasmusson, A., Uzunov, D. P., Costa, E., and Guidotti, A. (1998). Increase in the cerebrospinal fluid content of neurosteroids in patients with unipolar major depression who are receiving fluoxetine or fluvoxamine. Proc. Natl. Acad. Sci. U.S.A. 95, 3239-3244.

Uzunova, V., Wrynn, A. S., Kinnunen, A., Ceci, M., Kohler, C. and Uzunov, D. P. (2004). Chronic antidepressants reverse cerebrocortical allopregnanolone decline in the olfactory-bulbectomized rat. Eur. J. Pharmacol. 486, 31-34.

van Praag, H., Christie, B. R., Sejnowski, T. J., and Gage, F. H. (1999). Running enhances neurogenesis, learning, and long-term potentiation in mice. Proc. Natl. Acad. Sci. U.S.A. 96, 13427-13431. 
Velasco, I. (2011). Stem cells with neurogenic potential and steroid hormones. Curr. Top. Med. Chem. 11, 1684-1693.

Vermetten, E., Vythilingam, M., Southwick, S. M., Charney, D. S., and Bremner, J. D. (2003). Long-term treatment with paroxetine increases verbal declarative memory and hippocampal volume in posttraumatic stress disorder. Biol. Psychiatry 54, 693-702.

Viola, J., Ditzler, T., Batzer, W., Harazin, J., Adams, D., Lettich, L., and Berigan, T. (1997). Pharmacological management of posttraumatic stress disorder: clinical summary of a five-year retrospective study, 1990-1995. Mil. Med. 162, 616-619.

Wang, J. M., Johnston, P. B., Ball, B. G., and Brinton, R. D. (2005). The neurosteroid allopregnanolone promotes proliferation of rodent and human neural progenitor cells and regulates cell-cycle gene and protein expression. J. Neurosci. 25, 4706-4718.

Wang, J. M., Liu, L., Irwin, R. W., Chen, S., and Brinton, R. D. (2008). Regenerative potential of allopregnanolone. Brain Res. Rev. 57, 398-409.

Wang, J. M., Singh, C., Liu, L., Irwin, R. W., Chen, S., Chung, E. J., Thompson, R. F., and Brinton, R. D. (2010). Allopregnanolone reverses neurogenic and cognitive deficits in mouse model of Alzheimer's disease. Proc. Natl. Acad. Sci. U.S.A. 107, 6498-6503.

Waterhouse, E. G., and Xu, B. (2009). New insights into the role of brain-derived neurotrophic factor in synaptic plasticity. Mol. Cell. Neurosci. 42, 81-89.

Wetmore, C., Olson, L., and Bean, A. J. (1994). Regulation of brainderived neurotrophic factor (BDNF) expression and release from hippocampal neurons is mediated by non-NMDA type glutamate receptors. J. Neurosci. 14, 1688-1700.

Wieland, S., Lan, N. C., Mirasedeghi, S., and Gee, K. W. (1991). Anxiolytic activity of the progesterone metabolite 5 alpha-pregnan3 alpha-ol-20-one. Brain Res. 565, 263-268.

Wong, E. Y., and Herbert, J. (2004). The corticoid environment: a determining factor for neural progenitors' survival in the adult hippocampus. Eur. J. Neurosci. 20, 2491-2498.

Zhang, Z., Yang, R., Zhou, R., Li, L., Sokabe, M., and Chen, L. (2010). Progesterone promotes the survival of newborn neurons in the dentate gyrus of adult male mice. Hippocampus 20 , 402-412.

Conflict of Interest Statement: The authors declare that the research was conducted in the absence of any commercial or financial relationships that could be construed as a potential conflict of interest.

Received: 10 August 2011; paper pending published: 30 August 2011; accepted: 26 October 2011; published online: 21 November 2011.

Citation: Nin MS, Martinez LA, Pibiri F, Nelson M and Pinna G (2011) Neurosteroids reduce social isolation-induced behavioral deficits: a proposed link with neurosteroid-mediated upregulation of BDNF expression. Front. Endocrin. 2:73. doi: 10.3389/fendo.2011.00073

This article was submitted to Frontiers in Neuroendocrine Science, a specialty of Frontiers in Endocrinology.

Copyright (C) 2011 Nin, Martinez, Pibiri, Nelson and Pinna. This is an open-access article subject to a non-exclusive license between the authors and Frontiers Media $S A$, which permits use, distribution and reproduction in other forums, provided the original authors and source are credited and other Frontiers conditions are complied with. 